\title{
Observationally derived transport diagnostics for the lowermost stratosphere and their application to the GMI chemistry and transport model
}

\author{
S. E. Strahan ${ }^{1}$, B. N. Duncan ${ }^{1}$, and P. Hoor ${ }^{2}$ \\ ${ }^{1}$ Goddard Earth Science and Technology Center, University of Maryland, Baltimore County, Baltimore, MD 21250, USA \\ ${ }^{2}$ Max Planck Institute for Chemistry, Air Chemistry, Mainz, Germany
}

Received: 8 January 2007 - Published in Atmos. Chem. Phys. Discuss.: 29 January 2007

Revised: 24 April 2007 - Accepted: 27 April 2007 - Published: 11 May 2007

\begin{abstract}
Transport from the surface to the lowermost stratosphere (LMS) can occur on timescales of a few months or less, making it possible for short-lived tropospheric pollutants to influence stratospheric composition and chemistry. Models used to study this influence must demonstrate the credibility of their chemistry and transport in the upper troposphere and lower stratosphere (UT/LS). Data sets from satellite and aircraft instruments measuring $\mathrm{CO}, \mathrm{O}_{3}, \mathrm{~N}_{2} \mathrm{O}$, and $\mathrm{CO}_{2}$ in the UT/LS are used to create a suite of diagnostics for the seasonally-varying transport into and within the lowermost stratosphere, and of the coupling between the troposphere and stratosphere in the extratropics. The diagnostics are used to evaluate a version of the Global Modeling Initiative (GMI) Chemistry and Transport Model (CTM) that uses a combined tropospheric and stratospheric chemical mechanism and meteorological fields from the GEOS-4 general circulation model. The diagnostics derived from $\mathrm{N}_{2} \mathrm{O}$ and $\mathrm{O}_{3}$ show that the model lowermost stratosphere has realistic input from the overlying high latitude stratosphere in all seasons. Diagnostics for the LMS show two distinct layers. The upper layer begins $\sim 30 \mathrm{~K}$ potential temperature above the tropopause and has a strong annual cycle in its composition. The lower layer is a mixed region $\sim 30 \mathrm{~K}$ thick near the tropopause that shows no clear seasonal variation in the degree of tropospheric coupling. Diagnostics applied to the GMI CTM show credible seasonally-varying transport in the LMS and a tropopause layer that is realistically coupled to the UT in all seasons. The vertical resolution of the GMI CTM in the UT/LS, $\sim 1 \mathrm{~km}$, is sufficient to realistically represent the extratropical tropopause layer. This study demonstrates that the GMI CTM has the transport credibility required to study the impact of tropospheric emissions on the stratosphere.
\end{abstract}

Correspondence to: S. E. Strahan (sstrahan@pop600.gsfc.nasa.gov)

\section{Introduction}

Evaluation of transport between the upper troposphere (UT) and lower stratosphere (LS) is important because of the potential for tropospheric pollutants to impact stratospheric composition and chemistry. A decade ago, Ko et al. (1997) proposed that $\mathrm{Br}_{\mathrm{y}}$ produced from short-lived species in the tropical UT may contribute to stratospheric halogen loading, and a recent study using $\mathrm{BrO}$ measurements and photochemical models supports this hypothesis (Salawitch et al., 2005). More recently, a "tape recorder" of CO forced by seasonal variations in biomass burning was identified in the tropical UT/LS using satellite CO measurements (Schoeberl et al., 2006). Tropospheric pollutants with lifetimes of only a few months can affect the composition of the lowest portions of the stratosphere.

There are two major transport pathways to the stratosphere (Holton et al., 1995; Dessler et al., 1995). In the tropics, convection brings boundary layer air up to $\sim 12 \mathrm{~km}(\sim 345 \mathrm{~K})$, the base of the tropical tropopause layer (TTL) (Folkins, 2002). The TTL begins where convective mass flux falls off rapidly and extends to the cold point tropopause at $17-18 \mathrm{~km}$ (370-380 K) (Gettelman and Forster, 2002). Net heating rates become positive at about $16 \mathrm{~km}(\sim 360 \mathrm{~K})$ in the TTL and ascent by the Brewer-Dobson circulation slowly lifts air up to and across the tropical tropopause and into the stratosphere. A second pathway involves quasi-horizontal transport of air in the TTL to the extratropical lowermost stratosphere (LMS). This pathway is aided by monsoon anticyclones in the summer hemisphere (Chen, 1995), with poleward transport of tropospheric air on the west side and equatorward transport of stratospheric air on the east side of the monsoonal circulation.

The lowermost stratosphere is defined as the region between the extratropical tropopause, where isentropes connect the stratosphere and troposphere, and the stratospheric

Published by Copernicus Publications on behalf of the European Geosciences Union. 


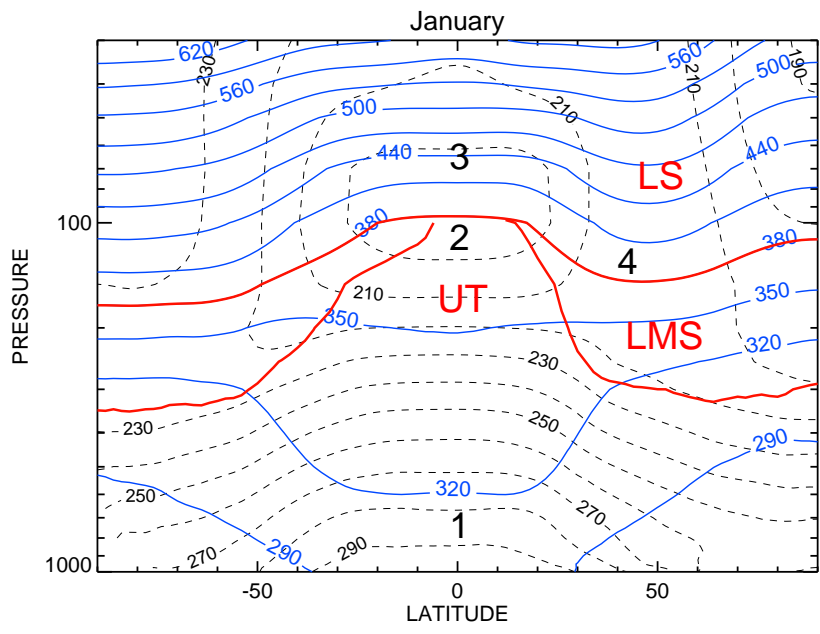

Fig. 1. Schematic diagram of the UT/LS derived from zonal monthly mean GEOS-4 meteorological analyses from January 2005. Temperature contours are black (dashed) and potential temperature contours are blue. The lowermost stratosphere, bounded by the $380 \mathrm{~K}$ potential temperature surface and the 2 PVU surface, is outlined in red. Transport between the numbered regions is discussed in the text.

overworld, where all isentropes are in the stratosphere (Fig. 1). This is the stratospheric part of the middleworld defined by Hoskins (1991). Air in the LMS has tropospheric and stratospheric origins, with the relative fractions varying by season. In winter, large potential vorticity (PV) gradients near the subtropical jet form an elastic, nearly impermeable barrier to cross-tropopause isentropic transport, much like that found at the edge of the polar vortex. Subtropical PV gradients are weaker in summer and evanescent waves from monsoonal circulations allow considerable stratosphere-troposphere exchange (STE) between the tropical UT and the LMS (Chen, 1995). Diagnostics of LMS transport, therefore, evaluate the integrated effects of the Brewer-Dobson (stratospheric) and monsoon (tropospheric) circulations.

There is agreement in the chemistry-climate model community on the need for diagnostics in the middleworld (Eyring et al., 2005). Numerous trace gas measurements in this region have large or seasonally-varying gradients across the tropopause, making them excellent indicators of the strength and timing of the dynamical processes affecting the middleworld. For example, Ray et al. (1999) used $\mathrm{CO}_{2}$ and CFC-11 profiles to demonstrate that the LMS composition changes from primarily stratospheric to tropospheric air between spring and fall. Similarly, Hoor et al. (2002) noted differences in the $\mathrm{CO}-\mathrm{O}_{3}$ correlation between winter and summer that indicated increased influence of tropospheric air in the LMS in July. Recently, Pan et al. (2007) have developed diagnostics for transport processes near the extratropical tropopause based on $\mathrm{CO}, \mathrm{O}_{3}, \mathrm{H}_{2} \mathrm{O}$, and variations in their mixing lines.
In this paper, we present diagnostics of middleworld transport and composition derived from satellite and aircraft measurements of $\mathrm{CO}, \mathrm{CO}_{2}, \mathrm{~N}_{2} \mathrm{O}$, and $\mathrm{O}_{3}$. Relevant dynamical processes include the ascent of tropical air from the surface to the stratosphere, the seasonally-varying transport from the tropical UT to the LMS, and the coupling between the extratropical UT and LMS. We also present a new version of the Global Modeling Initiative (GMI) chemistry and transport model (CTM) that uses meteorological fields from the GEOS-4 general circulation model (GCM) (Bloom et al., 2005) and has a chemical mechanism that includes tropospheric and stratospheric chemical reactions. The diagnostics are applied to this CTM, establishing the credibility of its UT/LS transport and supporting its use in studies of the impact of tropospheric emissions on lower stratospheric composition.

\section{Model and simulation descriptions}

The GMI CTM used in this study is related to the version described in Douglass et al. (2004) and references therein. The CTM uses a flux form semi-Lagrangian numerical transport scheme (Lin and Rood, 1996). The version of the model used here, referred to as the "GMI Combo", has a chemical mechanism that combines the stratospheric mechanism described in Douglass et al. (2004) with a modified version of the tropospheric mechanism originating in the Harvard GEOS-CHEM model (Bey et al., 2001). This combined mechanism contains 113 chemically active species, 315 chemical reactions and 78 photolytic processes. A new version of the Fast-J2 photochemical solver (Bian and Prather, 2002) called FastJX includes more bins for the calculation of stratospheric photolysis rates. Photolysis frequencies are computed using the Fast-JX radiative transfer algorithm, which combines the Fast-J tropospheric photolysis scheme described in Wild et al. (2000) with the Fast-J2 stratospheric photolysis scheme of Bian and Prather (2002) (M. Prather, personal communication, 2005). The scheme treats both Rayleigh scattering as well as Mie scattering by clouds and aerosols. The SMVGEAR II solver uses a 30-min timestep for the chemistry calculation, which is more accurate near the terminator than the 1-h timestep used in previous studies. Performance metrics of SMVGEAR II with respect to other solvers in the GMI stratospheric CTM can be found in Rotman et al. (2001). Model representation of physical processes in the troposphere, such as convection, wet scavenging, and dry deposition, are described in Duncan et al. (2007).

Long-lived source gases, such as $\mathrm{N}_{2} \mathrm{O}, \mathrm{CH}_{4}$, and the halocarbons, are forced at the two lowest levels with a mixing ratio boundary condition updated monthly, based on the A2 scenario (WMO, 2003). A climatology is used to specify the stratospheric distribution of water vapor each month. The GMI CTM calculates a change in water from the specified trend in methane and adds this to the climatology of each 
time step. $\mathrm{CO}_{2}$ is forced at the two lowest levels with a mixing ratio boundary condition using a time series derived from global surface observations (Conway et al., 1994) from a 17-yr period. The $\mathrm{CO}_{2}$ boundary condition has $10^{\circ}$-wide latitude bins with no longitudinal variability and is updated monthly. Model $\mathrm{CO}$ sources include emissions from biomass burning, fossil fuel consumption, biofuel use, lightning, and biogenics. They are treated as fluxes rather than mole fraction boundary conditions and are described in Duncan et al. (2007). This mechanism lacks a high altitude loss for $\mathrm{CO}_{2}$, a source of $\mathrm{CO}$, and thus the model $\mathrm{CO}$ is biased low in the stratosphere.

The CTM simulation evaluated here was run with meteorological fields from a 5-yr integration of the GEOS-4.0.2 GCM (Bloom et al., 2005). This integration was forced by observed sea surface temperatures for the period 19941998. The native resolution of the meteorological fields is $2^{\circ}$ latitude by $2.5^{\circ}$ longitude and 55 vertical levels with a lid at $0.015 \mathrm{hPa}$. The resolution in the UT/LS is $\sim 1 \mathrm{~km}$. To shorten the CTM integration time, the 24 levels above $10 \mathrm{hPa}$ were mapped to 11 levels using the method of Lin (2004); the top level is unchanged. The resulting CTM grid is $2^{\circ}$ latitude $\times 2.5^{\circ}$ longitude by 42 levels. A study of the effects of resolution and lid height on CTM transport characteristics determined that transport in the lower stratosphere and below is negligibly impacted by reduced resolution above $10 \mathrm{hPa}$ (Strahan and Polansky, 2006).

\section{Transport diagnostics in the upper troposphere and lower stratosphere}

Evaluation of the stratosphere in a CTM simulation integrated with meteorological fields from a GCM essentially evaluates extratropical wave driving in the GCM, the driver of the stratospheric circulation. A GCM that correctly simulates the generation, propagation, and dissipation of Rossby waves may correctly represent the global scale aspects of transport and STE (Holton et al., 1995). However, composition of the LMS depends on the interaction of UT processes with the Brewer-Dobson circulation. Thus, the diagnostics presented here evaluate the integrated effect of stratospheric and tropospheric processes on the UT/LS.

\subsection{Transport up to and through the tropical tropopause}

Changes in the amplitude and phase of the $\mathrm{CO}_{2}$ cycle observed at points 1 through 4 in Fig. 1 provide the basis for a series of transport diagnostics. Boering et al. (1996) (hereinafter referred to as B96) used ground-based $\mathrm{CO}_{2}$ measurements (Conway et al., 1994) along with NASA ER-2 aircraft data to estimate transport rates from the surface to the tropical tropopause, and from the tropical LS to the midlatitude LS. Figure 2 uses the B96 analysis to evaluate model transport from the surface to the tropical UT and beyond. B96
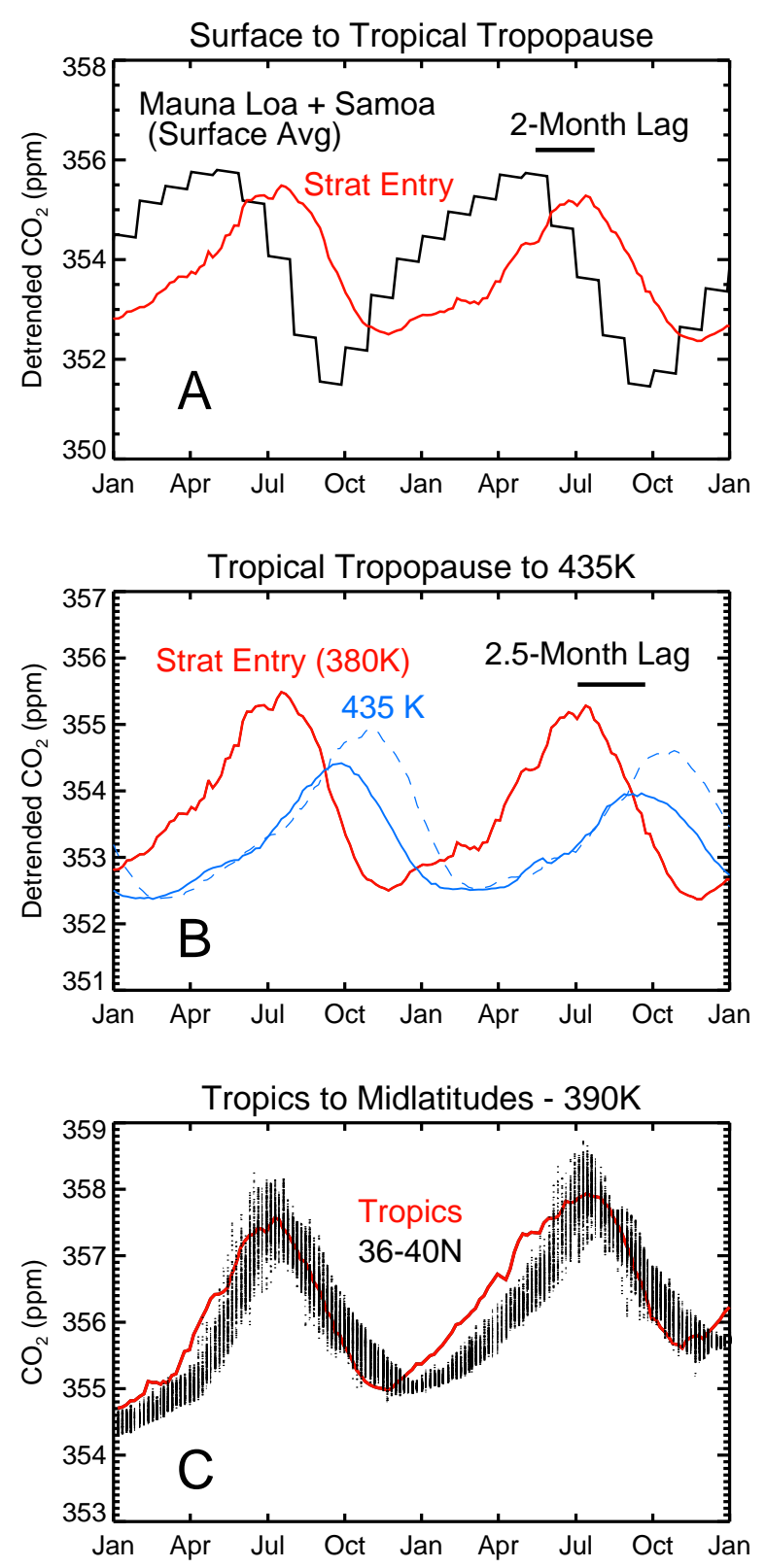

Fig. 2. Zonal mean $\mathrm{CO}_{2}$ seasonal cycles from two years of the GMI Combo CTM with the annual trend removed. (a) The black line is the average of Mauna Loa and Samoa model boundary conditions (derived from the NOAA Global Monitoring Division Flask Sampling Network) and the red line is the model tropical $\mathrm{CO}_{2}$ at the point of stratospheric entry $(380 \mathrm{~K})$. (b) The model tropical $\mathrm{CO}_{2}$ at stratospheric entry $(380 \mathrm{~K}$, red) is compared with the tropical cycle at $435 \mathrm{~K}$ (solid blue); there is a 2.5 month lag between them. The dashed blue line approximates how the model cycle should look if the attenuation and lag followed the aircraft results from B96. (c) The model tropical $\mathrm{CO}_{2}$ near stratospheric entry (red) and in the midlatitudes (black lines show variability), 380-400 K. In this panel, the annual trend is not removed because it does not hinder comparison of the amplitudes. 
showed that the seasonal cycle at tropical stratospheric entry $(380-390 \mathrm{~K})$ could be represented by the average of the surface cycles measured at Mauna Loa $\left(19^{\circ} \mathrm{N}\right)$ and Samoa $\left(14^{\circ} \mathrm{S}\right)$ time lagged by 2 months (Fig. 2a); this is the transport between points 1 and 2 in Fig. 1. The model results shown in Figs. 2a-b have the annual trend removed in order to clearly show the amplitude. The solid black line is the average of the model surface forcing at Mauna Loa and Samoa, which was derived from global observations (Conway et al., 1994). The model cycle at the tropical tropopause (red) is realistically lagged by 2 months, however, the amplitude is $\sim 1 \mathrm{ppm}$ less than observed by B96. This appears to be due the surface minimum (fall) arriving with a $\sim 1 \mathrm{ppm}$ increase in $\mathrm{CO}_{2}$. From the tropical tropopause, B96 found that the cycle was transported upward to $\sim 435 \mathrm{~K}$ in $3-4$ months, diminished in amplitude by $20 \%$; this is the transport between points 2 and 3 in Fig. 1 . If the model cycle at the tropopause (Fig. 2b, red) showed the same behavior, it would produce a cycle at $435 \mathrm{~K}$ shown by the dashed blue line in Fig. 2b. The actual model cycle at $435 \mathrm{~K}$ is shown by the solid blue line, which indicates that ascent is too rapid (the lag is 2.5 months) and that attenuation or horizontal exchange in the LS is too great, with 40\% loss of amplitude instead of $20 \%$. The loss of amplitude occurs during the ascent of the cycle maximum in late summer and fall, suggesting that the Brewer-Dobson circulation may be too strong in these seasons. Schoeberl et al. (2006) also assessed tropical ascent and horizontal mixing in this model from $14-20 \mathrm{~km}$ by comparison with the observed CO "tape recorder". They found that the model agreed well with the observed tilt of the CO signal (ascent rate) and the height at which the signal faded (horizontal mixing convolved with $\mathrm{CO}$ lifetime). While the tape recorder evaluation was only qualitative, it suggested that ascent and mixing throughout the year were roughly correct. The $\mathrm{CO}_{2}$ phase and attenuation comparison shown here is a stricter test of these processes and shows good agreement from midwinter to early summer, but suggests excess strength in late summer and fall.

B96 also examined poleward horizontal transport in the LS; this is the transport between points 2 and 4 in Fig. 1 . Their $\mathrm{CO}_{2}$ analysis used potential temperature and colocated $\mathrm{N}_{2} \mathrm{O}$ mixing ratios to create a vertical coordinate that effectively followed the extratropical tropopause, similar to the approach taken by Hoor et al. (2004), hereinafter referred to as $\mathrm{H} 2004$. They found that the $\mathrm{CO}_{2}$ cycle observed at the tropical tropopause could also be found near $\sim 38^{\circ} \mathrm{N}$, undiminished, with no more than a 1-month time lag. Figure $2 \mathrm{c}$ shows the model $\mathrm{CO}_{2}$ cycles in the tropics and from $36-40^{\circ} \mathrm{N}$, sorted by $\mathrm{N}_{2} \mathrm{O}=305-310 \mathrm{ppb}$ and potential temperature (theta) $=380-400 \mathrm{~K}$, just as in the $\mathrm{B} 96$ analysis. The near perfect match of the phase and amplitude of these cycles suggests realistic poleward transport in the lowest part of the stratospheric overworld. Notice that there is no lag in summer and fall, but roughly a 1 month lag in winter and spring. This is consistent with transport variations in the LMS de- scribed by Chen (1995) and Dunkerton (1995), who showed stronger exchange between the tropics and midlatitudes occurring in summer.

\subsection{The seasonally-varying composition of the lowermost stratosphere}

Several analyses have shown that the composition of the LMS varies considerably between winter and summer (e.g., Ray et al., 1999; Hoor et al., 2002; H2004; Krebsbach et al., 2006 and Hegglin et al., 2006). In winter and spring, the LMS has stratospheric character due to strong downward motion at mid and high latitudes, while large PV gradients across the subtropical jet restrict cross-tropopause transport. In summer, when downward advection by the Brewer-Dobson circulation is weak, the LMS has greater tropospheric character due to weak subtropical PV gradients which allow enhanced horizontal transport from the tropical UT to the LMS by the monsoonal anticyclones (Chen, 1995).

Ozone and $\mathrm{N}_{2} \mathrm{O}$ are useful as tracers of the origin of air because of their gradients across the tropopause. $\mathrm{N}_{2} \mathrm{O}$ and $\mathrm{O}_{3}$ have opposite source regions, the troposphere and stratosphere, respectively, and are long-lived in the LMS. Several datasets will be used to examine seasonal variations in lower stratospheric composition. The Microwave Limb Sounder (MLS) on the NASA Aura satellite provides daily measurements from $82^{\circ} \mathrm{S}-82^{\circ} \mathrm{N}$ for $\mathrm{O}_{3}(215 \mathrm{hPa}$ and above $)$ and $\mathrm{N}_{2} \mathrm{O}$ (100 hPa and above) (Waters et al., 2006). MLS vertical resolution is $\sim 3 \mathrm{~km}$ in the $\mathrm{LS}$ and $\sim 4 \mathrm{~km}$ on the $215 \mathrm{hPa}$ surface (middleworld). MLS $\mathrm{N}_{2} \mathrm{O}$ at $100-68 \mathrm{hPa}$ shows occasional high bias estimated to be generally less than $10 \%$; $\mathrm{MLS} \mathrm{O}_{3}$ has a reported bias of $1 \%$ in the stratosphere and $\sim 10 \%$ in the UT, and biases of $30-40 \%$ at pressures 200 $300 \mathrm{hPa}$ (Livesey et al., 2005). $\mathrm{N}_{2} \mathrm{O}$ data from eight SPURT aircraft campaigns are available in the extratropical LMS in all seasons (Engel et al., 2006). Seasonal mean analyses of ER-2 $\mathrm{N}_{2} \mathrm{O}$ and $\mathrm{O}_{3}$ data (Strahan et al., 1999; Strahan, 1999) provide profiles and latitudinal gradients from $360-500 \mathrm{~K}$. All aircraft data are used in equivalent latitude/potential temperature coordinates to eliminate spatial biases that may be caused by limited longitudinal sampling. Use of equivalent latitude extends the effective latitude range sampled by both aircraft to $\sim 87^{\circ} \mathrm{N}$. We use a dynamical definition of the tropopause, $2 \mathrm{PVU}$, where $1 \mathrm{PVU}=10^{-6} \mathrm{~m}^{2} \mathrm{~K} \mathrm{~s}^{-1} \mathrm{~kg}^{-1}$, to define the lower boundary of the LMS.

\subsection{1 $\mathrm{N}_{2} \mathrm{O}$}

The composition of the polar LS directly affects the LMS through downward transport by the Brewer-Dobson circulation. Low $\mathrm{N}_{2} \mathrm{O}$ descends in winter and spring, while in summer LMS composition is influenced by horizontal transport of higher (tropospheric) $\mathrm{N}_{2} \mathrm{O}$ from low latitudes. Figure 3 shows area-weighted contoured pdfs of model $\mathrm{N}_{2} \mathrm{O}$ and the most probable profile from pdfs of MLS $\mathrm{N}_{2} \mathrm{O}$ (black lines) 

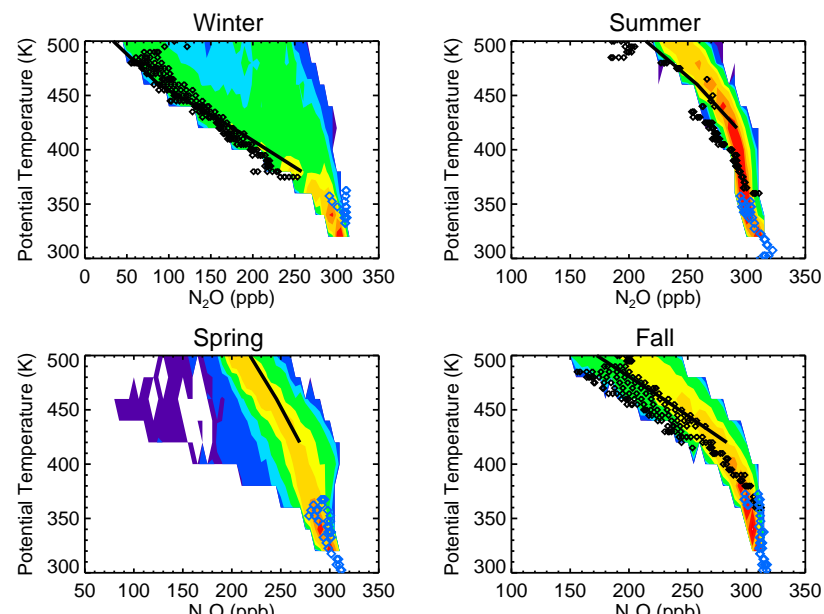

$\mathrm{N}_{2} \mathrm{O}(\mathrm{ppb})$

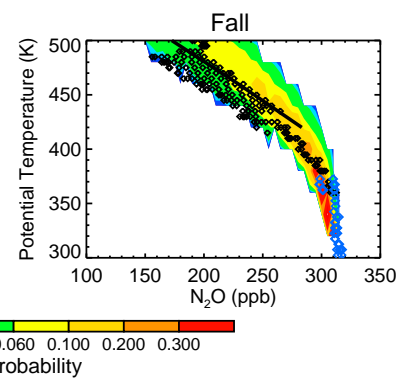

Fig. 3. Comparison of GMI and MLS high latitude $\mathrm{N}_{2} \mathrm{O}$ profiles $\left(70-82^{\circ} \mathrm{N}\right)$ in four seasons with SPURT and ER-2 profiles. GMI area-weighted contoured pdfs are calculated over the same seasonal sampling periods of the SPURT data (all months of the year except March, June, September, and December). Yellows and reds indicate sharply peaked distributions. MLS data are shown as most probable seasonal profiles (black line). ER-2 data (black diamonds) and SPURT data (blue diamonds) are seasonal means for equivalent latitudes $70^{\circ} \mathrm{N}-88^{\circ} \mathrm{N}$.

for latitudes $70^{\circ}-82^{\circ} \mathrm{N}$. Also plotted are seasonal mean $\mathrm{N}_{2} \mathrm{O}$ profiles from ER-2 (black diamonds) and SPURT (blue diamonds) analyses with equivalent latitudes $70^{\circ}-88^{\circ} \mathrm{N}$. The most probable values in winter represent the model mean vortex profile, while the large variability comes from profiles outside the vortex. (The spring ER-2 data are omitted because they are from 1997, a year with an unusually late vortex breakup (Coy et al., 1997).) The only disagreement with the data is found in summer and fall above $450 \mathrm{~K}$, where the model is up to $15 \%$ too high. Although the strength of descent and horizontal mixing cannot be judged independently, the excellent model agreement throughout most of the year at levels as low as $320 \mathrm{~K}$ suggests a very good balance of vertical and horizontal transport at levels of the polar LS affecting the LMS. The SPURT measurements are higher than the model in the LMS in winter, but this could be due to weaker descent in the warm Arctic winters during the SPURT campaigns (2002 and 2003). The model Arctic temperatures are near or below the real climatological mean.

Variability is an indicator of recent transport processes. In winter, large tracer gradients across the vortex edge coupled with wave-driven vortex displacements create high latitude pdfs showing large variability. Strong horizontal mixing in spring causes breakdown of the vortex and homogenization of long-lived trace gases in the extratropics. In summer, the well-mixed extratropics produce pdfs with very low variability because wave-driving is weak. Figure 4 shows contoured
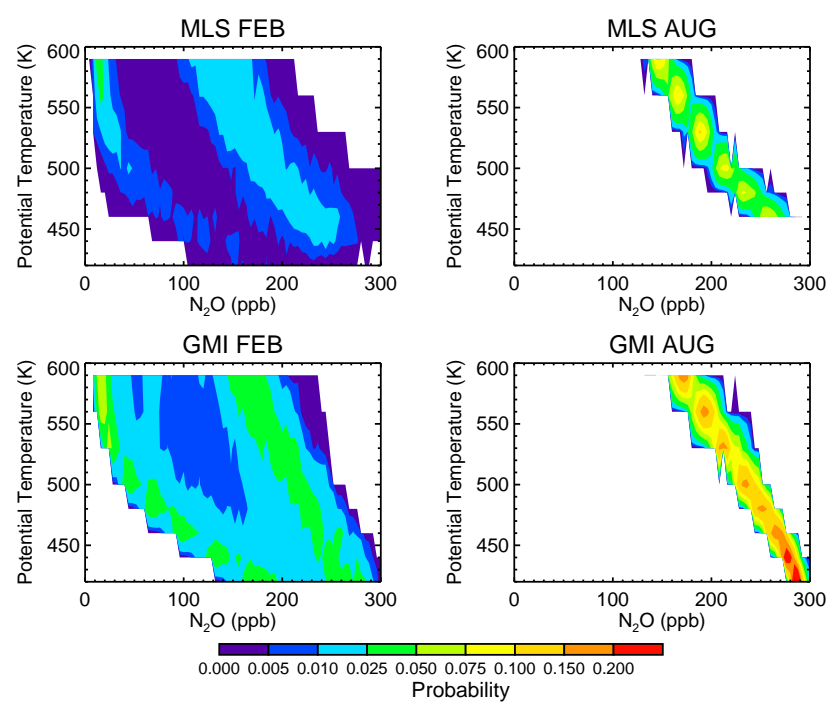

Fig. 4. Comparison of GMI and MLS winter and summer high latitude $\mathrm{N}_{2} \mathrm{O}$ profile variability $\left(66^{\circ}-82^{\circ} \mathrm{N}\right)$. MLS data are from 2005 and 2006. GMI variability is shown from two consecutive model years.

pdfs of MLS and GMI $\mathrm{N}_{2} \mathrm{O}$ profiles between $66^{\circ}-82^{\circ} \mathrm{N}$ in winter and summer, demonstrating the realistic seasonal variability of high latitude transport and mixing processes in the GMI Combo CTM. In February, excellent agreement between MLS and the model most probable profiles inside and outside the vortex, as well as the variability in both regions, shows that the model vortex is well isolated. The model has more mixing ratios between the two profiles, indicating slightly more mixing across the vortex edge. In summer, the MLS data and the model both show low variability characteristic of a well-mixed atmosphere with little wave-driving. Close agreement with MLS variability is also seen in the months not shown. Together, the comparisons in Figs. 3 and 4 are an important demonstration that LS transport processes in the GMI Combo CTM LS are credible and provide realistic input for the LMS in all seasons.

To examine seasonally-varying transport and composition in the LMS, we look at SPURT $\mathrm{N}_{2} \mathrm{O}$ in the dynamical coordinate system of equivalent latitude and potential temperature. We use equivalent latitude, which maps each measurement onto latitude according to its potential vorticity, because it removes variability caused by reversible wave transport (Butchart and Remsberg, 1986; Nash et al., 1996). H2004 and Hegglin et al. (2006) used this coordinate system to show that the isopleths of $\mathrm{CO}, \mathrm{N}_{2} \mathrm{O}$, and $\mathrm{O}_{3}$ follow $\mathrm{PV}$ rather than potential temperature contours in the LMS $(<360 \mathrm{~K})$ in all seasons.

GMI and SPURT $\mathrm{N}_{2} \mathrm{O}$ in the spring and fall, shown in Fig. 5, illustrate the seasonally changing composition of the LMS; the dashed lines overlays are PV contours $(2,4$, and 6 PVU). Note that the PV contours cross isentropes, that is, 

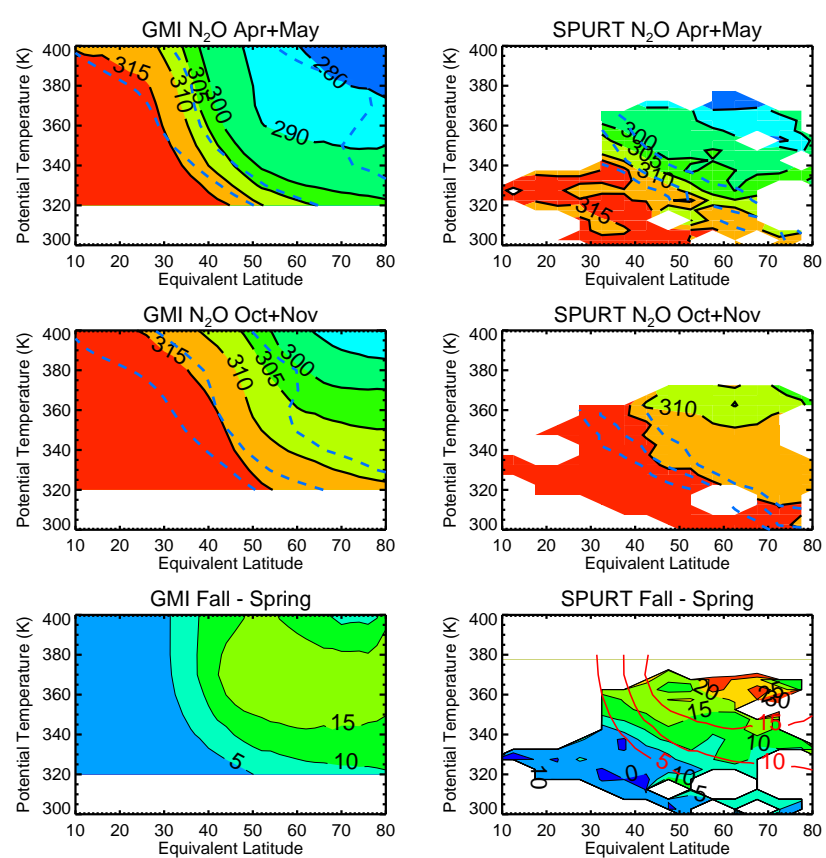

Fig. 5. Comparison of GMI and SPURT $\mathrm{N}_{2} \mathrm{O}$ in spring (April and May) and fall (October and November) in the lowermost stratosphere. Potential vorticity contours (2, 4, and 6PVU) are overlaid with dashed blue lines. The bottom panels show the fall-spring difference. The bottom right panel (SPURT) shows the model differences overlaid in red.

there are PV gradients on the isentropic surfaces. The PV gradients hinder isentropic transport, allowing time for diabatic cooling in the middleworld to move tracer isopleths downward as they are transported poleward. This is equivalent to the barrier to isentropic transport reported in Hegglin et al. (2006). The model $\mathrm{N}_{2} \mathrm{O}$ isopleths, like the data, follow the PV contours near the tropopause much more closely rather than they do isentropic surfaces, suggesting that the model has a reasonable balance between horizontal transport and diabatic cooling here. In all seasons except winter, model $\mathrm{N}_{2} \mathrm{O}$ mixing ratios are always within $2 \%$ of SPURT values. As noted before, SPURT values may be relatively high in winter due to weak descent in the observation years.

Composition differences between spring and fall are shown in the bottom panels of Fig. 5. In spring, downward advection by the Brewer-Dobson circulation is at a maximum, resulting in relatively low $\mathrm{N}_{2} \mathrm{O}$, and in fall, the downward circulation is weak while the influence of horizontal transport of high $\mathrm{N}_{2} \mathrm{O}$ from the TTL is greatest. This is consistent with the upper middleworld $(\geq 350 \mathrm{~K})$ results of Chen (1995), where seasonal mixing across the subtropical jet was found to be enhanced by the summer monsoon circulations. The composition difference is proportional to the seasonally changing tropospheric fraction of air in the LMS and is well represented by the model as a function of both height and latitude up to $\sim 360 \mathrm{~K}$, where the model appears to be less tropospherically influenced than the SPURT data.

\subsubsection{Ozone}

Ozone is also an excellent lower stratospheric transport tracer and use of its seasonal cycles has been advocated for the evaluation of model transport in the LMS (Logan, 1999). The availability of daily global MLS $\mathrm{O}_{3}$ measurements down to $215 \mathrm{hPa}$ allows evaluation of the entire middleworld. Ozone in this region is controlled largely by transport, although $\mathrm{O}_{3}$ production and loss are sensitive to local $\mathrm{NO}_{\mathrm{x}}$.

Figure 6 shows the annual cycle of $\mathrm{O}_{3}$ from the tropics to high latitudes, from 350-420 K using MLS data (black); GMI $\mathrm{O}_{3}$ is overlaid in red. The solid lines represent the mean values over the given latitude ranges, while the shading or hatching shows the full range of the variability. ER2 data are not used here because they are only available as seasonal means. GMI $\mathrm{O}_{3}$ shows close agreement with the observed MLS annual cycles and their variability, within the range of uncertainty reported for these data (Livesey et al., 2005). GMI $\mathrm{O}_{3}$ in the tropical UT is $30-50$ ppb lower than the MLS data, but as the MLS data may be biased between $10-40 \%$ at $215 \mathrm{hPa}$, a level that contributes to the $350 \mathrm{~K}$ surface, there is no definitive disagreement here. Simulated $\mathrm{O}_{3}$ agrees much more closely with the ozonesonde climatology of Logan (1999), where tropical $\mathrm{O}_{3}$ was found to range from $30-90 \mathrm{ppb}$ at $200 \mathrm{hPa}$, and with the tropical ozonesonde climatology of Folkins et al. (2006), where an average of 40$80 \mathrm{ppb}$ was found in the TTL. Agreement at $380 \mathrm{~K}$ in the tropics is within the $10 \%$ uncertainty reported for the MLS UT measurements. GMI high latitude $\mathrm{O}_{3}$ shows near perfect agreement in all seasons at all levels shown, except for the $350 \mathrm{~K}$ surface in summer and fall, where again, the 30-40\% MLS bias in $215 \mathrm{hPa}$ data could be a factor. GMI midlatitude $\mathrm{O}_{3}$ looks good in summer and fall but is low in winter. If the vortex were too isolated, the amount of high $\mathrm{O}_{3}$ mixed into the midlatitudes would be too low; however, Fig. 4 shows that the vortex is not overly isolated. If GMI tropical $\mathrm{O}_{3}$ is truly low, this could indicate too much transport to midlatitudes. Insufficient midlatitude descent, which has not been evaluated here, is also a possible cause. Overall, the agreement between observed and GMI mean $\mathrm{O}_{3}$ and its variability in the middleworld and LS is quite close, particularly in the context of the large range of mixing ratios observed here ( $\sim 100-2500 \mathrm{ppb})$. Because variability and seasonal composition are controlled primarily by transport, the $\mathrm{O}_{3}$ and $\mathrm{N}_{2} \mathrm{O}$ diagnostics demonstrate credible model transport throughout the year in the extratropical lower stratosphere from 320$500 \mathrm{~K}$.

\subsection{Stratosphere-troposphere coupling at the extratropical tropopause}

\subsubsection{CO}

CO has tropospheric sources and a lifetime of several months in the UT and LMS (Duncan et al., 2007). H2004 found 

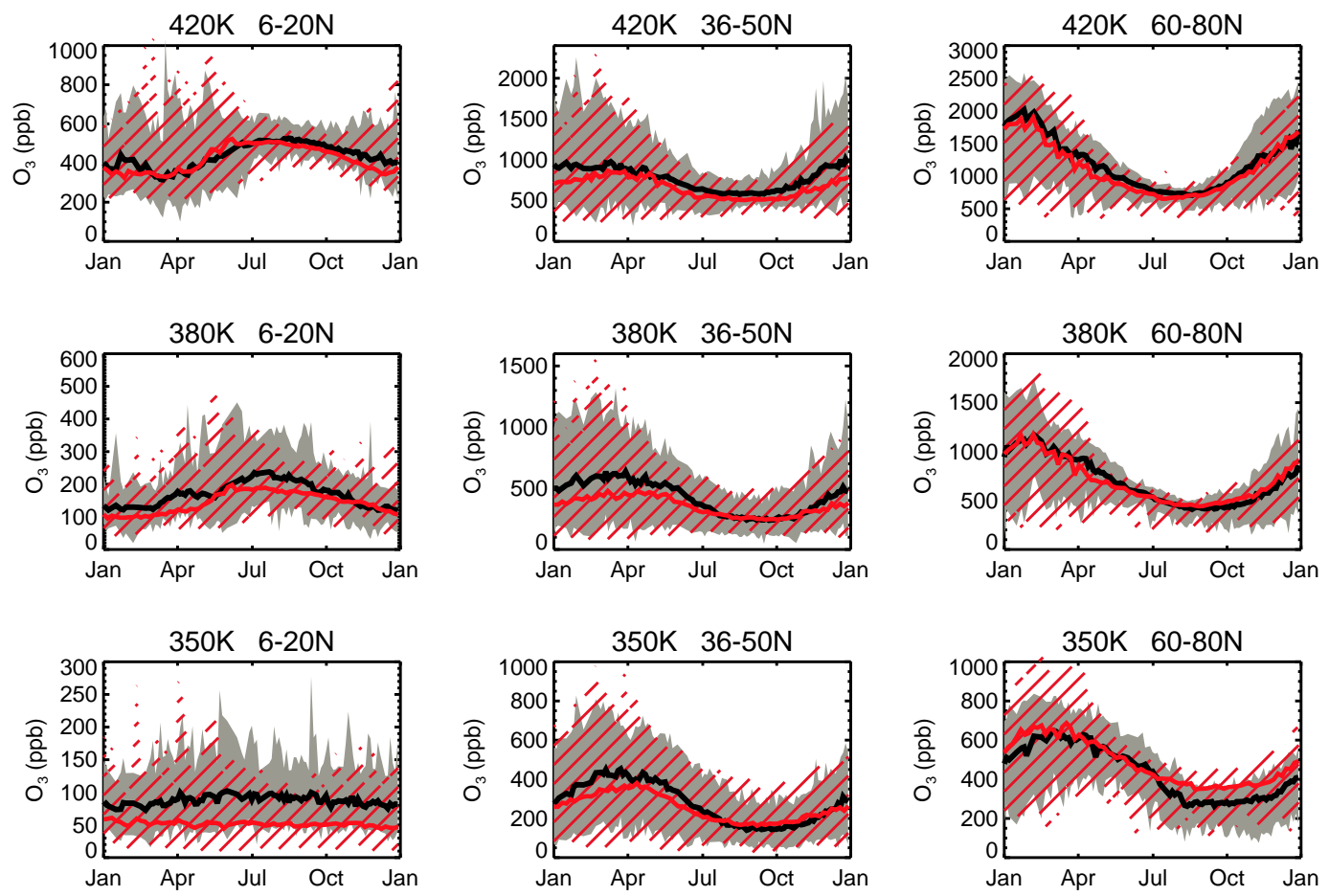

Fig. 6. Comparison of GMI (red) and MLS (black) $\mathrm{O}_{3}$ seasonal cycles for three latitude bands and 3 levels in the UT/LS. Solid lines are averages of all longitudes within the latitude band while the shading shows the full range of variability.

that SPURT CO profile data analyzed as a function of height relative to the dynamical tropopause ("delta theta") showed three distinct regions. At potential temperatures $25 \mathrm{~K}$ or more above the extratropical dynamical tropopause, defined as $2 \mathrm{PVU}$, they observed low CO mixing ratios and low variability characteristic of stratospheric air. Below the tropopause they observed high $\mathrm{CO}$ mixing ratios typical of the troposphere. From just below the tropopause to $25 \mathrm{~K}$ above it, a mixed layer was found that connected the two regions. The mixed layer had nearly constant thickness in all seasons and at all extratropical latitudes, although in summer it may have been slightly thicker $(\sim 30 \mathrm{~K})$. On an absolute scale, the mixed layer was almost always below the $350 \mathrm{~K}$ surface during the SPURT campaigns at latitudes $50^{\circ} \mathrm{N}$ or higher. These results are consistent with the tracer studies of Chen (1995), who reported that vigorous exchange between the stratosphere and troposphere occurred year-round at $330 \mathrm{~K}$ and below due to breaking synoptic scale baroclinic disturbances. H2004 concluded that the thickness of the mixed layer near the tropopause was a measure of the coupling between the stratosphere and troposphere. A recent analysis of $\mathrm{CO}$ and $\mathrm{O}_{3}$ high latitude aircraft measurements by Pan et al. (2007) determined that a well-defined mixed layer $\sim 2 \mathrm{~km}$ thick extended across the thermal tropopause. A 2-km layer near the tropopause spans $\sim 25 \mathrm{~K}$ potential temperature, making this result consistent with the $\mathrm{H} 2004$ findings.
We apply the results of the $\mathrm{H} 2004 \mathrm{CO}$ profile analysis to diagnose model extratropical stratosphere-troposphere coupling. To identify tropospheric or stratospheric character in the model, we evaluate histograms calculated from model CO in the 3 regions identified by the SPURT CO analysis: below the tropopause $(\leq-10 \mathrm{~K})$, the tropopause mixed layer $(-10 \mathrm{~K}$ to $25 \mathrm{~K})$, and the LMS ( $\geq 25 \mathrm{~K}$ above the tropopause). Figure 7 shows histograms for the seasons sampled by SPURT. The model distributions in the UT have mean values of $80-90 \mathrm{ppb}$ and show large variability. The distributions $\geq 25 \mathrm{~K}$ above the tropopause (LMS) are sharply peaked at $\sim 20 \mathrm{ppb}$, characteristic of stratospheric (aged) air. Notice that the UT and LMS distributions are almost completely non-overlapping indicating the distinctiveness of these regions. The extratropical tropopause layer (ExTL) has a CO peak of 30-40 ppb, which is closer to the stratospheric mean, but has a long tail with higher (tropospheric) CO mixing ratios. The ExTL distribution clearly has features that indicate a mixture of stratospheric and tropospheric air. The slight overlap of LMS and UT distributions in winter suggests that the model mixed layer extends a little higher than $25 \mathrm{~K}$ above the tropopause in this season.

We find that the thickness of the model mixed layer, like the results of the SPURT analysis (H2004), extends to $\sim 25 \mathrm{~K}$ above the dynamical tropopause in all seasons. This diagnostic suggests that the GEOS4-GCM meteorological fields used in the GMI Combo CTM provide reasonable forcing by 

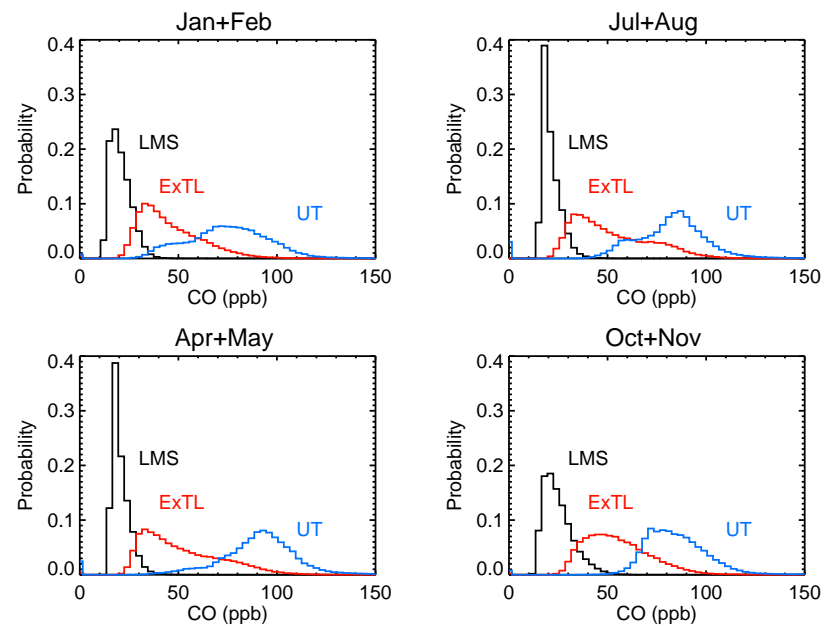

Fig. 7. Histograms of GMI Combo CO in the extratropical UT/LMS in four seasons. The UT distributions show points $10-50 \mathrm{~K}$ below the 2 PVU tropopause. The ExTL contains points from $10 \mathrm{~K}$ below to $25 \mathrm{~K}$ above the tropopause and the LMS distributions contain points from $25-80 \mathrm{~K}$ above the tropopause.

synoptic scale disturbances in the UT throughout the year to couple the troposphere with the lowest layers of the stratosphere. This also shows that the resolution of the GMI Combo CTM, $2^{\circ}$ latitude $\times 2.5^{\circ}$ longitude in the horizontal and $\sim 1 \mathrm{~km}(\sim 12 \mathrm{~K})$ in the vertical in the UT/LS, is sufficient to represent realistic coupling at the extratropical tropopause.

\subsection{2 $\quad \mathrm{CO}_{2}$}

The $\mathrm{CO}_{2}$ seasonal cycle phase and amplitude at the extratropical tropopause not only demonstrate the coupling between troposphere and stratosphere, but can be used to diagnose the influence of air arriving via the tropical stratosphere at levels above the coupling. Observed $\mathrm{CO}_{2}$ cycles in the UT and at the tropopause have a spring maximum and a large amplitude, but in the LMS the amplitude is much lower and the maximum occurs several months later (Nakazawa et al., 1991; B96; H2004). As has been demonstrated by analysis of observations in B96, Strahan et al. (1998), and H2004, the LMS cycle arrives via ascent through the tropical tropopause, followed by meridional poleward transport. The seasonal maximum that occurs in May in the northern mid-high latitude lower troposphere requires $\sim 3$ months to travel to the midlatitude LS via the tropical tropopause. H2004 observed that this transport pathway results in a reversed $\mathrm{CO}_{2}$ vertical gradient across the tropopause in late summer. The observations used in all of these analyses were collected over many decades, while $\mathrm{CO}_{2}$ increased at variable growth rates. Because aircraft measurements are sporadic in time and location, the phases and amplitudes of the cycles were determined from two or more years of observations in the analyses referenced. For these reasons, it makes more sense to

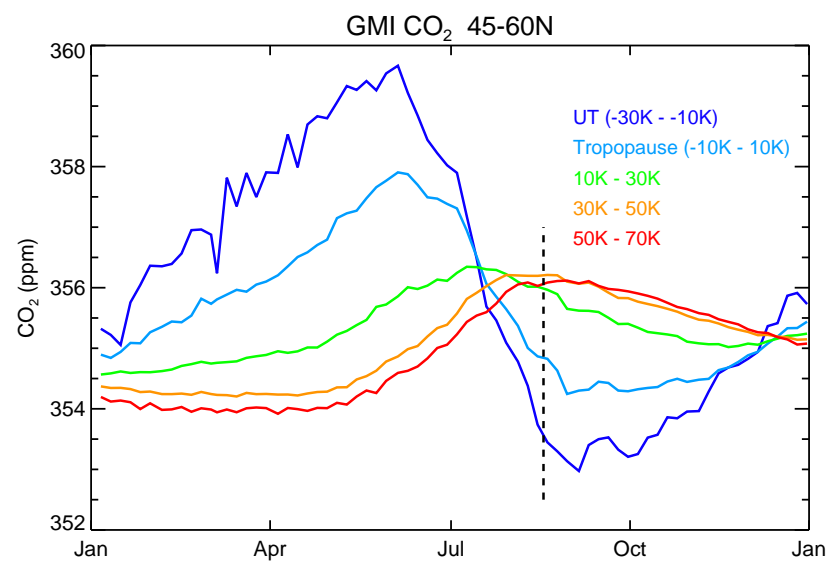

Fig. 8. GMI $\mathrm{CO}_{2}$ cycles below, at, and above the midlatitude tropopause $(2 \mathrm{PVU}), 45-60^{\circ} \mathrm{N}$. Each seasonal cycle is calculated over a $20 \mathrm{~K}$-wide vertical coordinate defined by the distance in potential temperature from the tropopause. The black dashed line marks the month when SPURT data show a reversed vertical gradient (H2004).

use the results of these analyses, rather than the observations themselves, for evaluating models.

Figure 8 shows the model $\mathrm{CO}_{2}$ cycles at several levels above and below the 2 PVU tropopause using the same 'delta theta' coordinate as H2004. The model cycles are computed by finding each grid point's distance in potential temperature from the 2 PVU level, binning those points into $20 \mathrm{~K}$ wide bins centered from $-20 \mathrm{~K}$ to $+60 \mathrm{~K}$ above the tropopause, then averaging over $45^{\circ}-60^{\circ} \mathrm{N}$ and all longitudes. In the UT and at the tropopause (blue), the model's cycles share two essential features of the analyzed UT observations: a large amplitude cycle ( $\sim 6 \mathrm{ppm})$ and a spring maximum. Just above the tropopause (green), the amplitude is much lower and the maximum occurs more than 1 month later. These features suggest a mixture of influences from above and below, consistent with the mixed layer diagnosed by the $\mathrm{CO}$ distributions (Fig. 7). At 30-70 K above the tropopause (orange and red), the cycle amplitudes are slightly greater than in the mixed layer $(10-30 \mathrm{~K})$ and the maximum is shifted to late summer. The higher amplitude is a characteristic of transport via the tropical tropopause and is seen at 40-60 K above the tropopause by $\mathrm{H} 2004$. The phase delay is also characteristic of this transport pathway and was observed in all the previously referenced $\mathrm{CO}_{2}$ studies. These essential features of the observational analyses are correctly produced by the model.

The reversed vertical gradient across the summer tropopause is another important transport feature correctly produced by the model (the dashed black line in Fig. 8). The reversed gradient occurs as a result of low $\mathrm{CO}_{2}$ in the summer UT, while the $\mathrm{CO}_{2}$ maximum that occurred in the spring is now arriving in the midlatitude LMS. In all other seasons $\mathrm{CO}_{2}$ decreases with height across the tropopause. 
Table 1. Transport diagnostics for the upper troposphere and lowermost stratosphere.

\begin{tabular}{|c|c|c|}
\hline Region or Process Diagnosed & Observationally-derived Diagnostic & Reference \\
\hline Tropical surface to UT & $\begin{array}{l}\mathrm{CO}_{2} \text { cycle phase and amplitude at tropical } \\
\text { stratospheric entry }(\sim 380 \mathrm{~K})\end{array}$ & Boering et al. (1996) \\
\hline $\begin{array}{l}\text { Troposphere to stratosphere } \\
\text { (vertical) }\end{array}$ & $\begin{array}{l}\mathrm{CO}_{2} \text { cycle phase and amplitude at the } \\
\text { tropopause and } 435 \mathrm{~K} \text { in tropics }\end{array}$ & Boering et al. (1996) \\
\hline $\begin{array}{l}\text { Horizontal poleward transport } \\
\text { (UT/LS) }\end{array}$ & $\begin{array}{l}\mathrm{CO}_{2} \text { cycle phase and amplitude at } \\
\sim 380 \mathrm{~K}, 40^{\circ} \mathrm{N}\end{array}$ & Boering et al. (1996) \\
\hline \multirow[t]{4}{*}{$\begin{array}{l}\text { Composition in the LMS and LS, } \\
\text { transport within the LMS }\end{array}$} & $\begin{array}{l}\mathrm{N}_{2} \mathrm{O} \text { Seasonal Profiles, } 70^{\circ}-82^{\circ} \mathrm{N}, 320- \\
500 \mathrm{~K}\end{array}$ & This study. \\
\hline & $\begin{array}{l}\mathrm{O}_{3} \text { seasonal cycle amplitude and variabil- } \\
\text { ity, tropics to high latitudes, } 350 \mathrm{~K}-420 \mathrm{~K}\end{array}$ & This study. \\
\hline & $\begin{array}{l}\text { Difference between Fall and Spring } \mathrm{N}_{2} \mathrm{O} \text {, } \\
320-380 \mathrm{~K}\end{array}$ & This study. \\
\hline & $\begin{array}{l}\mathrm{CO}, \mathrm{O}_{3} \text {, and/or } \mathrm{N}_{2} \mathrm{O} \text { isopleths following } \\
\text { the tropopause }\end{array}$ & $\begin{array}{l}\text { Hoor et al. (2004), } \\
\text { Hegglin et al. (2006) }\end{array}$ \\
\hline \multirow[t]{2}{*}{$\begin{array}{l}\text { Coupling at the extratropical } \\
\text { tropopause }\end{array}$} & $\begin{array}{l}\text { Consistent thickness of the tropopause } \\
\text { mixed layer }\end{array}$ & Hoor et al. (2004) \\
\hline & $\begin{array}{l}\text { Change in } \mathrm{CO}_{2} \text { cycle amplitude from the } \\
\text { UT to the LS }\end{array}$ & $\begin{array}{l}\text { Nakazawa et al. (1991), } \\
\text { Hoor et al. (2004) }\end{array}$ \\
\hline
\end{tabular}

The magnitude of the model reversed gradient, 2-3 ppm, is in good agreement with the $\mathrm{H} 2004$ analysis. A model run with convection turned off produced neither low $\mathrm{CO}_{2}$ in the summer UT nor the reversed gradient, demonstrating the importance of convection to correctly simulate composition near the tropopause.

\section{Diagnostics summary and GMI Combo CTM credi- bility}

Table 1 summarizes the suite of transport diagnostics presented in this paper. They have been applied to the GMI Combo CTM using GEOS4-GCM meteorological fields to evaluate transport from the tropical upper troposphere to lower stratosphere, composition of the lowermost stratosphere, and coupling between the extratropical troposphere and stratosphere. Most comparisons with data showed excellent agreement, but a few discrepancies were found in tropical LS transport. Upward transport and attenuation of the $\mathrm{CO}_{2}$ cycle from the tropical tropopause to $435 \mathrm{~K}$ showed ascent was too rapid in summer and fall, and mixing with midlatitudes was too great. This is consistent with summer polar $\mathrm{N}_{2} \mathrm{O}$ profiles that showed too much low latitude influence. The Brewer-Dobson circulation in the GEOS4-GCM appears to be too strong in the LS in the warm seasons.

The observationally-derived diagnostics indicate two distinct regions within the lowermost stratosphere. The lower region, found at and above the dynamical tropopause, is characterized as a mixture of tropospheric and stratospheric air that is $25-30 \mathrm{~K}$ thick year-round (H2004). The thickness of the model tropopause mixed layer agrees year-round with the H2004 CO analysis, and further evidence of the mixed layer and its thickness are provided by the phase and amplitude change of the $\mathrm{CO}_{2}$ cycle across the tropopause. The behavior of the model $\mathrm{CO}_{2}$ cycle is in good agreement with the Nakazawa et al. (1991) and H2004 results. This suggests that the UT wave disturbances involved in creating the mixed layer (Chen, 1995) operate realistically year-round. SPURT data analyses have shown that transport of long-lived species $\left(\mathrm{N}_{2} \mathrm{O}, \mathrm{O}_{3}\right.$, and $\left.\mathrm{CO}\right)$ follow isopleths of PV rather than potential temperature (Hoor et al., 2004; Hegglin et al., 2006). Model tracer transport also follows PV isopleths. Downward transport out of the LMS (stratosphere-to-troposphere flux) was not been evaluated here but was previously estimated for meteorological fields from the same GCM (Olsen et al., 2004). They compared ozone fluxes with empirically derived mass fluxes (Olsen et al., 2002) and found the absolute values and their seasonal variations in the GCM were reasonable.

The upper region of the LMS, which begins $\sim 30 \mathrm{~K}$ above the tropopause, is characterized by seasonally varying composition. This arises due to the seasonally-varying influence of the stratosphere (strong downward motion in winter) and troposphere (horizontal transport of tropical air via monsoon anticyclones in summer). Realistic model transport in this region is supported by $\mathrm{O}_{3}$ seasonal cycles from the tropics to high latitudes which match very well with MLS observations for 2005 , and by the difference between fall and spring $\mathrm{N}_{2} \mathrm{O}$, which shows the seasonal influence from the troposphere and 
matches the SPURT data very closely. Middleworld composition depends on the composition of stratospheric air descending from above, and the close agreement of high latitude $\mathrm{N}_{2} \mathrm{O}$ profiles with MLS, SPURT, and ER-2 data suggests realistic input from the overlying lower stratosphere in all seasons.

Model evaluation in the LS is an essential part of LMS evaluation because the LS is an input to the LMS. Realistic transport into and within the LMS depends on the BrewerDobson circulation in the meteorological fields used in the CTM. In the analysis of a similar CTM using GEOS4-GCM fields, Strahan and Polansky (2006) found that realistic LS transport barriers (e.g., those near the polar vortex and in the subtropics) were essential for obtaining credible $\mathrm{O}_{3}$ and $\mathrm{CH}_{4}$ distributions. Meteorological fields known to have good barriers (e.g., the GEOS4-GCM) require a CTM horizontal resolution of at least $2^{\circ} \times 2.5^{\circ}$ in order to correctly produce the barriers in the CTM. An important finding in this study is that a third mixing barrier, namely the mixed layer at the extratropical tropopause, can be credibly simulated using $2^{\circ} \times 2.5^{\circ}$ horizontal resolution and $\sim 1 \mathrm{~km}$ vertical resolution. Observationally-derived transport diagnostics used in Strahan and Polansky (2006) as well as several previous GMI studies are recommended for further evaluation of stratospheric transport (Douglass et al., 1999; Strahan and Douglass, 2004).

The realistic seasonal cycle of transport into and within the GMI Combo CTM lowermost stratosphere shown here demonstrates the utility of this model for studies of the influence of tropospheric composition on the LS, for example, Duncan et al. (2007). This model shows the appropriate transport time from the surface to the TTL, and in summer and fall, model transport from the TTL to the LS changes LMS composition in a realistic way. This demonstrates the feasibility of using this model to study the effects of tropospheric pollutants with lifetimes of a few months on the composition, chemistry, and radiative properties of the LMS. The seasonally varying $\mathrm{O}_{3}$ composition matches very well with observations, which supports the use of this model in studies involving perturbations to $\mathrm{O}_{3}$. While chemistry issues, not evaluated here, will be important for studying the impact of fire emissions and short-lived halogenated species on the stratosphere, this study has shown that the GMI Combo CTM can credibly represent important transport processes in the UT and LS.

Acknowledgements. This work was supported by the NASA Model Analysis and Prediction Program. We thank J. Rodriguez, Project Scientist of the Global Modeling Initiative for scientific support, and E. Nielsen for producing the GEOS-4-GCM meteorological fields. We also thank N. Livesey and L. Froidevaux for use of the MLS version 1.5 ozone data. We thank all the reviewers for constructive comments that improved this manuscript.

Edited by: M. Dameris

\section{References}

Bey, I., Jacob, D. J.,Yantosca, R. M., et al.: Global modeling of tropospheric chemistry with assimilated meteorology: Model description and evaluation, J. Geophys. Res., 106(D19), $23073-$ $23095,2001$.

Bian, H. and Prather, M. J.: Fast-J2: Accurate simulation of stratospheric photolysis in global chemical models, J. Atmos. Chem., 41, 281-296, 2002.

Bloom, S. C., da Silva, A. M., Dee, D. P., et al.: The Goddard Earth Observation System Data Assimilation System, GEOS DAS Version 4.0.3: Documentation and Validation, NASA TM-2005104606 V26, 2005.

Boering, K. A., Wofsy, S. C., Daube, B. C., Schneider, J. R., Loewenstein, M., Podolske, J. R., and Conway, T. J.: Stratospheric mean ages and transport rates from observations of $\mathrm{CO}_{2}$ and $\mathrm{N}_{2} \mathrm{O}$, Science, 274, 1340-1343, 1996.

Butchart, N. and Remsberg, E. E.: The area of the stratospheric polar vortex as a diagnostic of tracer transport on an isentropic surface, J. Atmos. Sci., 43, 1319-1339, 1986.

Chen, P.: Isentropic cross-tropopause mass exchange in the extratropics, J. Geophys. Res., 100, 16661-16674, 1995.

Conway, T. J., Tans, P. P., Waterman, L. S., and Thoning, K. W.: Evidence for interannual variability of the carbon-cycle from the National Oceanic and Atmospheric Administration Climate Monitoring and Diagnostics Laboratory Global Air Sampling Network, J. Geophys. Res., 99, 22 831-22 855, 1994.

Coy, L., Nash, E. R., and Newman, P. A.: Meteorology of the polar vortex: Spring 1997, Geophys. Res. Lett., 24, 2693-2696, 1997.

Dessler, A. E., Hintsa, E. J., Weinstock, E. M., Anderson, J .G., and Chan K. R.: Mechanism controlling water vapor in the lower stratsophere: A tale of two stratospheres, J. Geophys. Res., 100, 23 167-23 172, 1995.

Douglass, A. R., Prather, M. J., Hall, T. M., Strahan, S. E., Rasch, P. J., Sparling, L. C., Coy, L., and Rodriguez, J. M.: Choosing meteorological input for the global modeling initiative assessment of high-speed aircraft, J. Geophys. Res., 104, 27 545-27 564, 1999.

Douglass, A. R., Stolarski, R. S., Strahan, S. E., and Connell, P. S.: Radicals and reservoirs in the GMI chemistry and transport model: Comparison to measurements, J. Geophys. Res., D16303, doi:10.1029/2004JD004632, 2004.

Duncan, B. N., Strahan, S. E, and Yoshida, Y.: Model study of the cross-tropopause transport of biomass burning pollution, Atmos. Chem. Phys. Discuss., 7, 2197-2248, 2007, http://www.atmos-chem-phys-discuss.net/7/2197/2007/.

Dunkerton, T. J.: Evidence of meridional motion in the summer lower stratosphere adjacent to monsoon regions, J. Geophys. Res., 100, 16 675-16688, 1995.

Engel, A., Boenisch, H., Brunner, D., et al.: Highly resolved observations of trace gases in the lowermost stratosphere and upper troposphere from the SPURT project: an overview, Atmos. Chem. Phys., 6, 283-301, 2006,

http://www.atmos-chem-phys.net/6/283/2006/.

Eyring, V., Harris, N. R. P., Rex, M., et al.: A strategy of processoriented validation of couple chemistry-climate models, Bull. Am. Met. Soc., doi:10.1175/BAMS-86-8-1117. 2005.

Folkins, I.: Origin of lapse rate changes in the upper tropical troposphere, J. Atmos. Sci., 59, 992-1005, 2002.

Folkins, I., Bernath, P., Boone, C., Donner, L. J., Eldering, 
A., Lesins, G., Martin, R. V., Sinnhuber, B.-M., and Walker, K.: Testing convective parameterizations with tropical measurements of $\mathrm{HNO}_{3}, \mathrm{CO}, \mathrm{H}_{2} \mathrm{O}$, and $\mathrm{O}_{3}$ : Implications for the water vapor budget, J. Geophys. Res., 111, D23304, doi:10.1029/2006JD007325, 2006.

Gettelman, A. and Forster, P. M. de F.: A Climatology of the tropical tropopause layer, J. Met. Soc. Japan, 80, 911-924, 2002.

Hegglin, M. I., Brunner, D., Peter, T., et al.: Measurements of NO, $\mathrm{NO}_{\mathrm{y}}, \mathrm{N}_{2} \mathrm{O}$, and $\mathrm{O}_{3}$ during SPURT: implications for transport and chemistry in the lowermost stratosphere, Atmos. Chem. Phys., 6, 1331-1350, 2006,

http://www.atmos-chem-phys.net/6/1331/2006/.

Holton, J. R., Haynes, P. H., McIntyre, M. E., Douglass, A. R., Rood, R. B., and Pfister, L.: Stratosphere-troposphere exchange, Rev. Geophys., 33, 403-439, 1995.

Hoor, P., Fischer, H., Lange, L., and Lelieveld, J.: Seasonal variations of a mixing layer in the lowermost stratosphere as identified by the $\mathrm{CO}-\mathrm{O}_{3}$ correlation from in situ measurements, J. Geophys. Res., 107, D4044, doi:10.1029/2000JD000289, 2002.

Hoor, P., Gurk, C., Brunner, D., Hegglin, M. I., Wernli, H., and Fischer, H.: Seasonality and extent of extratropical TST derived from in-situ CO measurements during SPURT, Atmos. Chem. Phys., 4, 1427-1442, 2004,

http://www.atmos-chem-phys.net/4/1427/2004/.

Hoskins, B. J.: Toward a PV-theta view of the general circulation, Tellus, Ser. A, 43, 27-35, 1991.

Ko, M. K. W., Sze, N. D., Scott, C. J., and Weisenstein, D. K.: On the relation between stratospheric chlorine/bromine loading and short-lived tropospheric source gases, J. Geophys. Res., 102, 25 507-25 517, 1997.

Krebsbach, M., Schiller, C., Brunner, D., Guenther, G., Hegglin, M. I., Mottaghy, D., Riese, M., Spelten, N., and Wernli, H.: Seasonal cycles and variability of $\mathrm{O}_{3}$ and $\mathrm{H}_{2} \mathrm{O}$ in the UT/LMS during SPURT, Atmos. Chem. Phys., 6, 109-125, 2006,

http://www.atmos-chem-phys.net/6/109/2006/.

Lin, S.-J.: A vertically Lagrangian finite-volume dynamical core for global models, Mon. Wea. Rev., 132, 2293-2307, 2004.

Lin, S.-J. and Rood, R. B.: Multidimensional flux-form semiLagrangian transport schemes, Mon. Wea. Rev., 124, 20462070, 1996.

Livesey, N., Read, W. G., Filipiak, M. J, et al.: Earth Observing System (EOS) Microwave Limb Sounder (MLS) Version 1.5 Level 2 data quality and description document, JPL D-32381, 2005.

Logan, J. A.: An analysis of ozonesonde data for the lower stratosphere: Recommendations for testing models, J. Geophys. Res., 104, 16 151-16 170, 1999.

Nakazawa, T., Miyashita, K., Aoki, S., and Tanaka, M.: Temporal and spatial variations of upper tropospheric and lower stratospheric carbon dioxide, Tellus Ser. B, 43, 106-117, 1991.

Nash, E. R., Newman, P. A., Rosenfield, J. E., and Schoeberl, M. R.: An objective determination of the polar vortex using Ertel's potential vorticity, J. Geophys. Res., 101, 9471-9478, 1996.

Olsen, M. A., Douglass, A. R., and Schoeberl, M. R.: Estimating downward cross-tropopause ozone flux using column ozone and potential vorticity, J. Geophys. Res., 107, D4636, doi:10.1029/2001JD002041, 2002.
Olsen, M. A., Schoeberl, M. R, and Douglass, A. R.: Stratospheretroposphere exchange of mass and ozone, J. Geophys. Res., 109, D24114, doi:10.1029/2004JD005186, 2004.

Pan, L. L., Wei, J. C., Kinnison, D. E., Garcia, R. R., Wuebbles, D. J., and Grasseur, G. P.: A set of diagnostics for evaluating chemistry-climate models in the extratropical tropopause region, J. Geophys. Res, 112, doi:10.1029/2006JD007792, in press, 2007.

Ray, E. A., Moore, F. L., Elkins, J. W., Dutton, G. S., Fahey, D. W., Vomel, H., Oltmans, S. J., and Rosenlof, K. H.: Transport into the Northern Hemisphere lowermost stratosphere revealed by in situ tracer measurements, J. Geophys. Res., 104, 26 565-26 580, 1999.

Rotman, D. A., Tannahill, J. R., Kinnison, D. E., et al.: Global Modeling Initiative assessment model: Model description, integration, and testing of the transport shell, J. Geophys. Res., 106, 1669-1691, 2001.

Salawitch, R. S., Weisenstein, D. K., Kovalenko, L. J., Sioris, C. E., Wennberg, P. O., Chance, K., Ko, M. K. W., and McLinden, C. A.: Sensitivity of ozone to bromine in the lower stratosphere, Geophys. Res. Lett., 32, L05811, doi:10.1029/2004GL021504, 2005.

Schoeberl, M. R., Duncan, B. N., Douglass, A. R., Waters, J., Livesey, N., Read, W., and Filipiak, M.: The carbon monoxide tape recorder, Geophys. Res. Lett., 33, L12811, doi:10.1029/2006GL026178, 2006.

Strahan, S. E.: Climatologies of lower stratospheric $\mathrm{NO}_{y}$ and $\mathrm{O}_{3}$ and correlations with $\mathrm{N}_{2} \mathrm{O}$ based on in situ observations, J. Geophys. Res., 104, 30 463-30 480, 1999.

Strahan, S. E., Douglass, A. R., Nielsen, J. E., and Boering, K. A.: The $\mathrm{CO}_{2}$ seasonal cycle as a tracer of transport, J. Geophys. Res., 103, 13 729-13 742, 1998.

Strahan, S. E., Loewenstein, M., and Podolske, J. R.: Climatology and small-scale structure of lower stratospheric $\mathrm{N}_{2} \mathrm{O}$ based on in situ observations, J. Geophys. Res., 104, 2195-2208, 1999.

Strahan, S. E. and Douglass, A. R.: Evaluating the credibility of transport processes in simulations of ozone recovery using the Global Modeling Initiative three-dimensional model, J. Geophys. Res., 109, D05110, doi:10.1029/2003JD004238, 2004.

Strahan, S. E. and Polansky, B. C.: Meteorological implementation issues in chemistry and transport models, Atmos. Chem. Phys., 6, 2895-2910, 2006, http://www.atmos-chem-phys.net/6/2895/2006/.

Waters, J., Froidevaux, L., Harwood, R. S., et al.: The Earth Observing System Microwave Limb Sounder (EOS MLS) on the Aura satellite, IEEE Trans. Geosci. Rem. Sens., 44, 1075-1092, 2006.

Wild, O., Zhu, X., and Prather, M.: Fast-J: Accurate simulation of in- and below-cloud photolysis in tropospheric chemical models, J. Atmos. Chem., 37, 245-282, 2000.

World Meteorological Organization (WMO): Scientific assessment of ozone depletion: 2002, WMO 47, Geneva, Switzerland, 2003. 